\title{
Epidemiology and Seroprevalence of Human Immunodeficiency Virus Type 2
}

\author{
Bineeta Kashyap Hitender Gautam Preena Bhalla \\ Department of Microbiology, Maulana Azad Medical College, New Delhi, India
}

\section{Key Words}

HIV-2 • Integrated counseling and testing center •

Coinfection $\cdot$ Risk factors

\begin{abstract}
HIV-2 infection is detected sporadically mostly from the southern states of India. We did a retrospective analysis to find the seroprevalence of HIV-2 in and around Delhi. The study included all attendees of an integrated counseling and testing center (ICTC) from January 2004 to January 2009. As per NACO guidelines, samples showing positive results in three rapid tests were declared HIV-positive. Samples that were reactive for HIV-2 were further confirmed by Western blot assay. $8.8 \%(n=1,938)$ of the clients were reactive for HIV-1, 0.03\% ( $n=6)$ were reactive for HIV-2 and $0.005 \%(n=$ 1) had HIV-1 and HIV-2 coinfection. Spouses of only 2 cases were tested, both resulting as nonreactive. History of travel or past stay to endemic states was present in $57 \%$ cases. The commonest risk factor revealed in them was sexual contact with commercial sex workers (86\%). As such, seroprevalence of HIV-2 is very low but continued surveillance is needed for HIV-2 to understand the epidemiology and natural history of this complex human pathogen.
\end{abstract}

Copyright $\odot 2010$ S. Karger AG, Basel
India has a population of 1.1 billion people - one sixth of the world's population - and is home to perhaps 1 of every 8 people with HIV infection. The first case of HIV1 infection was identified in Chennai in 1986, and since then India has had an epidemic of HIV infection and AIDS with an estimate of around 2.4 million individuals currently living with HIV/AIDS in India [1].

In 1985, a second type of HIV, called HIV-2, was first described in asymptomatic West African prostitutes, following which, in 1986, it was reported in 2 West Africans with AIDS. Infection with HIV-2 poses a serious concern in West Africa and is becoming recognized more frequently in other parts of the world. It is believed that HIV2 infection spread from West Africa, where it is endemicsporadic, to other more distant African countries and out of Africa into Europe, North America and Asia. In Europe, Portugal and France reported the highest number of cases among homosexual men, intravenous drug users, transfusion recipients and hemophiliac men [2]. In the Western hemisphere, rare cases of HIV-2 infection have also been reported from Brazil, Canada, and the United States. In Asia, 95\% of the reported HIV-2 cases were from India [3].

HIV-2 is a close relative to HIV-1. Both these viruses produce similar clinical illness and share many proper-

\section{KARGER}

Fax +4161306 1234 E-Mail karger@karger.ch www.karger.com
Dr. Bineeta Kashyap

Flat No. C-402, Vimal CGHS Ltd.

Plot No. 3, Sector-12

Dwarka, New Delhi 110075 (India)

E-Mail dr_bineetakashyap@yahoo.co.in 
Table 1. Year-wise comparison of seroprevalence of HIV-1 and HIV-2 (Jan. 2004-Jan. 2009)

\begin{tabular}{lllll}
\hline Year & $\begin{array}{l}\text { Total } \\
\text { patients }\end{array}$ & $\begin{array}{l}\text { HIV-1- } \\
\text { positive }\end{array}$ & $\begin{array}{l}\text { HIV-2- } \\
\text { positive }\end{array}$ & $\begin{array}{l}\text { HIV-1 and HIV-2 } \\
\text { coinfection }\end{array}$ \\
\hline 2004 & 3,859 & 259 & 0 & 1 \\
2005 & 5,657 & 362 & 2 & 0 \\
2006 & 4,211 & 352 & 0 & 0 \\
2007 & 3,715 & 477 & 0 & 0 \\
2008 & 4,192 & 450 & 3 & 0 \\
2009 & 299 & 38 & 1 & 0 \\
\hline Total & 21,933 & 1,938 & 6 & 1 \\
\hline
\end{tabular}

ties such as CD4 cell tropism, mode of transmission and morphology, but differ at the molecular, clinical and epidemiological levels. Though human infection with HIV2 is associated with eventual immunologic failure and AIDS, disease progression has been reported to be much slower in HIV-2- compared with HIV-1-infected individuals, as evidenced by significantly slower rates of development of abnormal CD4 $\mathrm{T}$ cell counts and progression to AIDS [4].

Although HIV-2 infection probably originated in West Africa, it may, like HIV-1, come to pose a significant concern on other continents. As HIV-2 infection is increasingly being recognized throughout the world, studies of the epidemiology, natural history, therapy, and biology of this complex human pathogen will be needed to assess more accurately the length of the asymptomatic period and the percentage of infected persons in whom AIDS or related syndromes eventually develop. Hence, a retrospective analysis of all attendees of an integrated counseling and testing center (ICTC) (during January 2004January 2009) was undertaken to find the prevalence of HIV-2 infection in and around Delhi.

The study included all attendees of an ICTC during January 2004 and January 2009. The ICTC is located within the Department of Microbiology, Maulana Azad Medical College and the associated Lok Nayak Hospital which is a tertiary care hospital in Delhi, India.

As per the policy and strategy prescribed by the National AIDS Control Organization (NACO) [5], informed consent was taken from the patients and pre-test counseling was carried out. The samples were tested for HIV by using a rapid test (HIV Comb, based on Dot immunoassay, rapid visual test for the qualitative detection of antibodies to HIV-1 and HIV-2 in human serum/plasma/ whole blood, manufactured by J. Mitra \& Co., Pvt. Ltd., Delhi) following the manufacturer's instructions. If the sample tested nonreactive by the first rapid test, the patient was given a nonreactive report. However, if the sample tested reactive by the first rapid test then according to the guidelines two more rapid tests (Retroquic, membrane based flow through immunoassay for the detection of antibodies to HIV-1 and HIV-2 in human serum or plasma, manufactured by Qualpro Diagnostics Goa and Acon HIV 1/2/0 Tri-line Human Immunodeficiency Virus, rapid chromatographic immunoassay test device in whole blood/serum/plasma, manufactured by Rapid Diagnostics Pvt. Ltd., India) were done on the same sample following the manufacturer's instructions. At least one of the above-mentioned tests should be able to differentiate between HIV-1 and HIV-2 according to the guidelines. If the sample was reactive by all the three rapid tests then the patient was given a HIV-reactive report after doing post-test counseling. The samples which were reactive for HIV-2 infection were confirmed by Western blot assay for the detection of HIV antibodies in human serum/ plasma (HIV W.Blot, manufactured by J. Mitra \& Co. Pvt., Ltd.) following manufacturer's instructions. The presence or absence of antibodies in a serum sample is determined by comparing each strip with the negative and positive control strips in Western blot assay.

Of the total 21,933 clients who visited the ICTC during the study period, 1,938 were reactive for HIV-1 giving an overall prevalence of $8.8 \%$ for HIV-1. Only 6 of the total 21,933 clients attending the ICTC were reactive for HIV-2 giving a seroprevalence of $0.03 \%$ for HIV-2. One patient of the total attendees was reactive for both HIV-1 and HIV-2 giving the seroprevalence of $0.005 \%$ for HIV- 1 and HIV-2 coinfection (table 1). Since the first evidence of HIV-2 infection in India in 1991, HIV-2 has been reported from various regions of the country, including HIV-1 and HIV-2 dual infections. Studies from different parts of India have shown a varied prevalence of HIV-2 alone and HIV-1 and HIV-2 dual infection. Data from south India showed a prevalence of $2.1 \%$ for dual infections and 0.13 to $1.8 \%$ for HIV-2 infection alone [6]. Reports from Western parts of India showed seroprevalence rates in high-risk groups varying from 5 to $20 \%$ for dual infection [3]. A systematic seroepidemiological study in a STD cohort of Pune, Maharashtra, has confirmed that HIV-2 infections and dual infections with HIV-1 and HIV-2 accounted for 1.7 and $4.7 \%$, respectively [7].

Among all the antibody-reactive cases, HIV-1 infection amounted to $99.64 \%$, HIV-2 and HIV-1 and HIV-2 coinfection amounted to 0.31 and $0.05 \%$, respectively. 
Table 2. Details of cases with HIV-2 infection

\begin{tabular}{|c|c|c|c|c|c|c|c|}
\hline & $\begin{array}{l}\text { Case } 1 \\
\text { (coinfection) }\end{array}$ & Case 2 & Case 3 & Case 4 & Case 5 & Case 6 & Case 7 \\
\hline Age/sex & $35 / \mathrm{M}$ & $32 / \mathrm{M}$ & $37 / \mathrm{M}$ & $18 / \mathrm{M}$ & $49 / \mathrm{M}$ & $27 / \mathrm{M}$ & $60 / \mathrm{M}$ \\
\hline Occupation & caterer & factory worker & truck driver & laborer & factory worker & laborer & factory worker \\
\hline Spouse & negative & not tested & not tested & unmarried & negative & not tested & not tested \\
\hline Travel history & present & absent & $\begin{array}{l}\text { present } \\
\text { (South India) }\end{array}$ & absent & $\begin{array}{l}\text { present (South India) origins } \\
\text { from Chennai but stayed in } \\
\text { Bombay for last } 10-12 \text { years }\end{array}$ & not known & $\begin{array}{l}\text { stayed in Bombay } \\
\text { alone for } 30-32 \\
\text { years }\end{array}$ \\
\hline Risk factor & $\begin{array}{l}\text { extramarital } \\
\text { heterosexual }\end{array}$ & CSW & CSW & CSW & $\begin{array}{l}\text { MSM } \\
\text { CSW } \\
\text { blood transfusion }\end{array}$ & CSW & CSW \\
\hline $\begin{array}{l}\text { Reason for } \\
\text { testing }\end{array}$ & $\begin{array}{l}\text { symptomatic } \\
\text { referred }\end{array}$ & $\begin{array}{l}\text { symptomatic } \\
\text { referred }\end{array}$ & asymptomatic & $\begin{array}{l}\text { symptomatic } \\
\text { referred STD }\end{array}$ & diarrhea, weight loss & $\begin{array}{l}\text { symptomatic } \\
\text { STD }\end{array}$ & $\begin{array}{l}\text { referred from chest } \\
\text { clinic }\end{array}$ \\
\hline $\begin{array}{l}\text { Duration } \\
\text { of history }\end{array}$ & 10 years & $6-8$ years & $12-13$ years & $2-3$ years & $12-13$ years & not known & $15-20$ years \\
\hline OI & $\begin{array}{l}\text { cryptococcal } \\
\text { meningitis }\end{array}$ & cryptosporidiosis & - & - & - & - & $\mathrm{TB}$ \\
\hline
\end{tabular}

The epidemiological and clinical details of all the 6 HIV-2 reactive cases and 1 case of HIV-1 and HIV-2 coinfection are given in table 2 .

Among the HIV-2 cases, all were males whose age ranged between 18 and 60 years.

As regards the occupational status, 3 were factory workers, 2 were laborers and 1 was a truck driver. The HIV-1 and HIV-2 coinfection case was a caterer by profession. Studies from across the world have linked migration to multiple sexual partners and increased HIV transmission [8]. It has been said that migrants and other mobile individuals are bridge populations for HIV transmission from urban to rural areas and between high-risk and low-risk groups. All the HIV-2-reactive cases in our study were in a profession that led them to migrate from one place to another. Coming to the marital status of these HIV-infected individuals, all were married (including the one who had HIV-1 and HIV-2 coinfection) except for 1 who was 18 years old.

Out of the total 7 cases (6 HIV-2 and 1 HIV-1 and HIV2 coinfection) in our study, only $28.57 \%$ of the total patients reactive for HIV-2 were direct walk-in clients to our ICTC which speaks of the AIDS-related stigma that refers to the prejudice and discrimination directed at people living with HIV/AIDS (PLWHA). The epidemic of fear, stigmatization and discrimination has undermined the ability of individuals, families and societies to protect them. Of these 2 clients who came to the ICTC volun- tarily 1 was asymptomatic and the other had come with presenting complaints of weight loss and diarrhea of few months' duration. The remaining 5 patients, including the coinfection case, were referred clients from the various wards of the hospital to which our ICTC is attached. Among the 5 referred clients, 2 (40\%) had presented with some genital problem and were referred from the STD clinic, another $2(40 \%)$ were referred from the medical ward due to some undiagnosed chronic illness and the remaining $1(20 \%)$ was symptomatic for pulmonary tuberculosis and was referred from the chest clinic.

As regards the interval between the approximate time of exposure history and time of presentation for these cases, for all the cases except the 1 who was 18 years old and was referred from the STD clinic, the range was $10-$ 20 years. The 18 -year-old client referred from the STD clinic gave 2-3 years' history of exposure. The clinical spectrum associated with HIV-1 infection is well known and has been described in many developing countries. On the other hand, there are only a limited number of studies concerning the natural history and the clinical manifestations associated with HIV-2 infection. The epidemiological and biological characteristics of HIV-1 and HIV-2 exhibit major differences and the reasons for these important differences are not fully understood. From 1985 to 1993, a prospective clinical study conducted in women with HIV-2 and HIV-1 infection to determine and compare rates of disease development con- 
cluded that HIV-1-infected women had a $67 \%$ probability of AIDS-free survival 5 years after seroconversion in contrast with $100 \%$ for HIV-2-infected women. In addition to having significantly less HIV-related disease outcome in HIV-2 enrollees compared to HIV-1 enrollees, the rate of developing abnormal $\mathrm{CD} 4+$ lymphocyte counts with HIV-2 infection was also significantly reduced. This natural history study demonstrates that HIV-2 has a reduced virulence compared to HIV-1 [9]. This is also evident in our study by the fact that the interval between the approximate time of exposure history and time of presentation for all these cases except 1 ranged between 10 and 20 years. Estimates indicate that the rate of progression to CDC stage IV disease is 3-4 times greater for HIV-1 than for HIV-2 and that the rate of progression to overt AIDS is 12-13 times greater. Individuals infected by HIV-2 are, therefore, less likely to develop AIDS or, at least, will have a much longer asymptomatic period [10].

Of all 7 HIV-2 cases, 6 (85.7\%), including the 18 -yearold unmarried client had a history of sexual contact with commercial sex workers (CSWs). Staying away from family for longer durations due to professional commitment was the most common reason given for this. In addition to the history of sexual contact with CSWs, other risk factors for HIV-2 in our study were blood transfusion and MSM (men having sex with men). The HIV-1 and HIV-2 coinfection case gave a history of getting involved in an extramarital heterosexual contact. History of travel or past stay ( $>1$ year) to Mumbai and Chennai was present in 4 (57\%) cases. HIV-2 appears to be transmitted in West Africa principally by sexual contact, with prostitutes being the well-studied group. The virus can also be spread by contact with infected blood, such as with transfusion. Rates of both heterosexual transmission and perinatal transmission of HIV-2 are much lower than those for HIV-1. These differences are reflected in the different patterns of the HIV-1 and HIV-2 epidemics; while HIV-1 has spread virtually worldwide over the past 20 years, HIV-2 has largely been confined to West Africa. Very few cases have been reported outside these countries as HIV-2 is not easily transmitted during the lengthy asymptomatic phase of infection due to the very low levels of virus found during this time. One study recently reported that viral load, as measured by levels of viral RNA in the plasma, is much lower in HIV-2- than in HIV-1-infected individuals, despite similarities in age at infection and time infected. Inadequate activation is responsible for low plasma viral load in HIV-2 infection [11]. Another study showed that HIV-2 infection is char- acterized by a significantly lower plasma viral set point than HIV-1 infection and that the HIV-2 plasma viral load early after seroconversion was similar to the levels observed in other studies among HIV-1-infected persons with long-term nonprogression. It also appears that dual infection has unpredictable consequences for HIV-1 and HIV-2 plasma viral load [12]. This was also seen in our study as the spouses of 2 cases that we could follow-up were found to be nonreactive. The perinatal transmission pattern of HIV-2 is less compared to that of HIV-1. In one study, it was found that at least $30 \%$ of babies born to mothers infected with HIV-1 are infected, whereas no more than $10 \%$ of infants born to HIV-2-infected mothers appear to be infected [10]. It has been theorized that the low rate of transmission may result from lower viral titers in the blood of HIV-2 patients compared with those infected with HIV-1. This low rate of transmission suggests that either the HIV-2 cannot replicate efficiently in human cells or replication is controlled by an effective immune response. These data provide a compelling explanation for the differences in the natural course, transmissibility, and epidemiological characteristics of HIV-1 and HIV-2, as well as new insights into the biological interplay between the two viruses in individuals exposed to both.

As regards the AIDS-associated illness/OIs (opportunistic infections) that these cases finally became diagnosed with, 3 of the total 7 cases were diagnosed with some OIs, 1 was diagnosed to have cryptosporidiosis and another had pulmonary tuberculosis. The HIV-1 and HIV-2 coinfection case was diagnosed to have cryptococcal meningitis.

Diagnostic tests for HIV-2 have recently been reviewed. Infection with HIV-2 must be strongly considered in patients who either come from endemic areas, particularly West Africa, or have sexual partners from those regions. From our experience concerning diagnostic testing for HIV-2 in a region where prevalence is extremely low, we conclude that assays capable of detecting both HIV-1 and HIV-2 must continue to be used for screening and/or diagnosis of HIV infections. An HIV-2/HIV-1 combination ELISA and an HIV-2-specific ELISA are commercially available. Infection with HIV-2 can be confirmed by Western blot. In patients with equivocal serology or those infected too recently to have seroconverted (most patients infected with HIV-1 seroconvert within 3 months, the interval to HIV-2 seroconversion has not yet been determined), the polymerase chain reaction might prove helpful in making the diagnosis of HIV-2 infection. Thus, to address the 
problem related to HIV-2, continued surveillance is needed to monitor HIV-2 in our population because the possibility for further spread of HIV-2 exists, especially among people with multiple sex partners. Programs aimed at preventing the transmission of HIV-1 also can help to prevent and control the spread of HIV-2. As HIV-2 infection is increasingly recognized throughout the world, further studies of the epidemiology, natural history, therapy, and biology of this complex human pathogen will be needed.

\section{References}

1 Steinbrook R: HIV in India - a complex epidemic. N Engl J Med 2007;356:1089-1093.

2 O'Brien TR, George JR, Epstein J, Holmberg S, Schochetman G: Testing for antibodies to human immunodeficiency virus type 2 in the United States. Morb Mortal Wkly Rep 1992;41:1-9.

-3 Kannangai R, Ramalingam S, Prakash KJ, et al: Molecular confirmation of human immunodeficiency virus (HIV) type 2 in HIV-seropositive subjects in south India. Clin Diagn Lab Immunol 2000;7:987-989.

4 Schramm B, Penn ML, Palacios EH, Grant RM, Kirchhoff F, Goldsmith MA: Cytopathicity of human immunodeficiency virus type 2 (HIV-2) in human lymphoid tissue is coreceptor dependent and comparable to that of HIV-1. J Virol 2000;74:9594-9600.
5 WHO: Anti-Retroviral Therapy Guidelines for HIV-Infected Adults and Adolescents Including Post-Exposure Prophylaxis. NACO, 2007. Available from http://upaidscontrol. up.nic.in/Guidelines/Antiretroviral\%20 Therapy\%20Guidelines\%20for\%20HIV\%20 infected $\% 20$ Adults $\% 20$ an.pdf [cited on 2009/12/05]

-6 Murugan S, Anburajan R: Prevalence of HIV-2 infection in south Tamil Nadu. Indian J Sex Transm Dis 2007;28:113.

7 Kulkarni SS, Tripathy S, Paranjape RS, et al: Isolation and preliminary characterization of two HIV-2 strains from Pune, India. Indian J Med Res 1999;109:123-130.

8 Saggurti N, Verma RK, Jain A, RamaRao S, Kumar KA, Subbiah A et al: HIV risk behaviours among contracted and non-contracted male migrant workers in India: potential role of labour contractors and contractual systems in HIV prevention. AIDS 2008; 22:S127-S136
-9 Marlink R, Kanki P, Thior I, et al: Reduced rate of disease development after HIV-2 infection as compared to HIV-1. Science 1994; 265:1587-1590.

10 Kanki PJ: Biologic features of HIV-2: an update. AIDS Clin Rev 1991:17-38

$>11$ Popper SJ, Sarr AD, 'Ye-ndiaye AG, Mboup S, Essex ME, Kanki PJ: Low plasma human immunodeficiency virus type 2 viral load is independent of proviral load: low virus production in vivo. J Virol 2000;74:1554-1557.

12 Andersson S, Norrgren H, da Silva Z, et al: Plasma viral load in HIV-1 and HIV-2 singly and dually infected individuals in GuineaBissau, West Africa. Arch Intern Med 2000; 160:3286-3293 